\title{
Study on the Value Orientation of College Literature Education in the New Era
}

\author{
Li Qi \\ School of Foreign Studies, Xi'an University, 710065
}

Keywords: Colleges and Universities; Literature; Education and Teaching; Value Orientation

\begin{abstract}
Education is the foundation of a country's prosperity and development and the most important support point of China's strategy to empower the country. Higher education is the most prominent part in our educational system, which is determined not only by the status of higher education, but also by the major responsibilities and missions of higher education. In the new historical period, the teaching of literature education in colleges and universities in China should aim at the training of talents and adhere to the correct value orientation of education and teaching.
\end{abstract}

Nowadays, with economic and social development, globalization has become an irreversible trend. In the context of the wave of globalization, all kinds of thoughts and cultures are emerging one after another. Whether it is to insist on being oneself or follow the trend and to absorb or abandon the new contents in the face of temptation and distress, a person's value plays a decisive role in how to make a scientific judgment. In the new historical period, the teaching of literature education in colleges and universities in China shoulders more historical responsibility and mission than ever before. It is necessary to cultivate professional literary talents with high literacy, but also to focus on value-oriented traction and do a good job in moral education.

The education and teaching reforms promoted at this stage in China are formulated with the aim of improving the all-round quality of talents. In this strategy, literature education is at the top of the entire chain. Excellent literary works are not only the precious spiritual wealth of all mankind, but also a good carrier for guiding and educating people's character. Effectively carrying out literature education teaching has important and practical significance for promoting the all-round development of students morally, intellectually, physically and aesthetically.

\section{Current Status of Literature Education and Teaching at Colleges and Universities}

After years of development, the literature education and teaching at colleges and universities in China has formed a good system. However, with the deepening of education reform and the improvement of the social demand for talents, the response of the entire higher literature education to this change is still slow, and their drawbacks have already been revealed at many places. On the whole, the author believes that the current situation of literature education at colleges and universities in China has the following shortcomings: 


\subsection{A Little Bit Obsolete Ideas and Concepts}

The concept of education and teaching has a strong guiding role in the entire educational system. At present, China's demand for talents has undergone fundamental changes. In order to adapt to this change, education and teaching reform has been carried out in all aspects, both in theoretical exploration and in practice. But many schools and teachers are slow to respond to this change. Some colleges and universities have insufficient understanding of the role played by literature education in teaching reform, and even pay insufficient attention. Some colleges have fewer literature and education courses, which cannot ensure the needs of students' literary cultivation. Some people think that literature education teaching only needs to follow the traditional model, and there is no need to make any changes. Some students also believe that literature education teaching is not quite helpful for future work, and psychologically reduces the importance of literature education. It is the teaching and learning that has caused the overall literary education and teaching at colleges and universities in China to stagnate. For many people, to rejuvenate the country with hard work is only an empty talk. These people believe that the teaching of literature education is not an entity, at most it is embellished, and there is not much substantial promotion of social development and progress. There are still a few people who hold this view, so that some parents regret to send students into the literature profession. At present, the data from colleges and universities have already reflected the negative impact of this mentality.

\subsection{The Impact of Diversified Culture}

The Internet has entered and profoundly affected every aspect of our lives. In the context of the Internet, various electronic books have affected the entire generation with irreversible influence. Among them, the impact of young students is the first to bear the brunt. They are willing to accept new things and are willing to find themselves in the network and let go of themselves. At present, the influence of online fast-food literature on students has aroused widespread concern in the whole society. According to survey data, online literature has become the main front for young students to read, and their interest in traditional serious literature has plummeted. In a fashionable saying, now that you don't read online novels, it seems that college life is incomplete. Here, we are not amplifying the harm of online literature, but we must see the crisis faced by traditional literature education.

\subsection{The Backwardness of Teaching System}

The reason why many students are uninterested in the traditional literature education teaching has a great relationship with the current situation of our college literature education teaching system. In the course content setting, the textbook content has been revised many years, and many students are not interested in seeing these subjects far away from their real life; Some schools also arrange a certain number of literature courses in their freshman year, but when they are in their sophomore year, they will not be arranged in the third year. This leads some students to think that the literature course is a foil, and there is little relationship between learning and not learning. This obviously runs counter to the systematic and persistent nature emphasized in the teaching of literature education. Today, with the popularization of various advanced teaching methods, literature education teaching is still dominated by classroom teaching. The networked and modularized literature education teaching system is obviously insufficiently invested and constructed. 


\section{Value of Literature Education and Teaching}

We have never stopped the exploration of the value of literature education. Since ancient times, literature education has received extensive attention. The value of literature education teaching can generally be summarized into three aspects: education, cognition and aesthetics. The educational function of literature has its unique value and charm whenever it is. This kind of educational function is obviously different from ideological and political education, and more is done in a subtle way. Therefore, the educational function of literature is persistent and sticky. It is often created through the appreciation of literary works, through the reading of vivid characters and beautiful language. In this process, readers can not only feel the power of beauty, but also their own life, and finally achieve the goal of unifying action and consciousness.

Literature is art, and literature education is summarized by many teachers as a kind of aesthetic education. Literary education generally starts with image thinking and enhances the individual's ability to think in terms of emotional education. Literary works are presented to the readers in the form of a holistic and visualized spiritual product. It has a completely different approach to abstract thinking. Literary works can greatly enhance people's thinking ability and teach people a keen sense of inspiration and unlimited creativity. Literary works directly affect people's emotions, enriching people's emotional world. Good literary works can resonate strongly between the author and the reader, allowing the author to treat life and things with highly aesthetic standards.

At present, under the impact of diverse cultural backgrounds, the entire social culture shows instability. Young students, due to their knowledge structure and social experience, have low speculative abilities and are easily affected by many negative factors. Many students can't stand the test and temptation like this, lose their own value pursuit, and blindly follow the trend of drifting. Hedonism, egoism, money worship and other ideological trends invade the spiritual world of teachers and students. The uneven values of online literature have intensified the differentiation of young students' value trends. Under the influence of these popular literature, some students have low aesthetic tastes. They no longer maintain awe of traditional serious literature and are more willing to accept those superficial fast food features. The emergence of this situation has aroused widespread vigilance in the whole society. Many people of insight in society have raised this issue to the height of national cultural protection.

At present, China's education and teaching reform has entered the deep-water area. The society has also undergone major changes in the demand for talent. High-quality literary talents should not only have the corresponding professional knowledge. How to do a good job in the new era of college literature education teaching in the talent training role is related to the success or failure of literature education teaching reform.

In the teaching of literature education in the new era, we must focus on cultivating the true nature of students. Being true is the foundation of literature. Only authentic literary works can achieve the purpose of probation. Literature itself is a science based on the background of truth. We must educate students to dare to seek truth. Mr. Lu Xun is a famous writer in modern China. The key point of his work is that he deeply influenced the generation. The key point of Mr. Lu Xun's work is to make a real effort in realizing his work. His works truly show the society at that time. Hundreds of states accurately express the suffering of the people. The ideology of young students is still in the stage of formation. We must teach them to treat different things with a realistic attitude, instead of blindly obeying and accepting. The stories and characters in excellent literary works can inspire the students to overcome difficulties and work hard.

In the teaching of literature education in the new era, we must focus on cultivating students' goodness. Young students shoulder the responsibility of inheriting China's excellent moral traditions and promoting friendly culture. At present, as a whole, China's social atmosphere is not optimistic, 
and there have been landslides in many places. If young students discard kindness even at the very least, then our social value system will be in jeopardy. Therefore, we must vigorously cultivate students' sense of friendship, and let students learn to be good at others and to cultivate them to be a kind, fair and responsible person.

\section{Measures to Improve the Teaching Value Guidance of College Literature Education in the New Period}

To do a good job in the value-oriented work of literature education at colleges and universities in the new era, the author believes that it should focus on the following aspects:

\subsection{Attaching Importance Ideologically}

From a certain perspective, literary education is an important branch of humanities education, and it is also an important support for the entire social education system. For the guiding role of the value of college literature education in the new era, we should have a clear and profound understanding. We must abandon the interference of the misconceptions of the past and do a good job in the overall reform of the literature education in the new era. It is necessary to focus on strengthening the comprehensive humanistic qualities of college teachers and students and adopt various measures to actively shape and nurture students' good moral awareness and nationalist sentiments. From the perspective of the school, we must work hard to create a great atmosphere for the benign development of literature education and teaching. We should collect the needs of teachers and students in the construction of education and teaching systems, and proceed from the actual situation of the school to protect the discipline construction; The majority of teachers should take the overall requirements of the times and the overall situation of discipline construction as their own responsibility, do their due diligence, and fully tap the great role of literature education and teaching in the reform of higher education teaching; The majority of students should have a full consideration of the social value of literature education and teaching, and should not examine this subject from a one-sided perspective.

\subsection{Sticking to the Main Position of Traditional Literature Teaching}

We do not exclude online literature, but we are not invisible to the impact of online literature on the healthy growth of young students. We must adhere to the main position of traditional literature education and teaching, and cultivate students' true, good, and beautiful with high-quality traditional literary works to cultivate students' sentiments and guide students to correctly understand and solve problems. Let them use these excellent works to understand life, to think about life, and to explore life. In the curriculum setting, we should take the clues of discipline as the discipline of planning and construction and strive to maintain the continuity and persistence of literature education.

\subsection{Changing the Traditional Education and Teaching Mode}

The teaching of literature education in colleges and universities is slightly dull compared with other disciplines. At the same time, because the teaching of literature education is more abstract, the teaching is more difficult. Traditional literature education teaching has not deviated from the idea of blackboard chalk. Nowadays, various high-tech auxiliary education teaching methods have been widely used in classroom teaching. However, looking at the teaching of Chinese literature education, it seems that the research on the application of high-tech technology in education and teaching is 
still lagging behind. Young students are at a special stage in their lives. They are more interested in new things. New ways of teaching and teaching tend to stimulate their enthusiasm and initiative. Judging from the application effect of new technology education and teaching methods, it is indeed more advantageous than the traditional way. We must work hard to change the traditional teaching mode of college literature education, combine tradition with modernity, and completely change the current education and teaching dilemma.

\section{References}

[1] Liu Cong. Innovative Research on College Education Model under the Background of “Internet + " [J].Modern Vocational Education, 2017(16):116-117.

[2] Хи Lihua. On the Role of Literary Education in Cultivating College Students' Socialist Core Values [J].Heilongjiang Education, 2016, (6).

[3] Yang Xiaomeng. Thinking and Exploring the Humanities Quality Education of College Students [J]. Young Literary, 2014, (2).

[4] Yu Congcong. Literature Education: A Question of Spiritual Person and Life Value [J]. Read and Write Monthly, 2016, (27).

[5] Zhang Aihua. The Dilemma and Way Out for College Literature Education under the Background of Internet [J]. Comparative Research on Cultural Innovation, 2017, 1(21):53-54.

[6] Zhang Ranran. On the University Literature Education in the 21st Century [J]. Contemporary Education Practice and Teaching Research, 2016, (3).

[7] Zhang Ying. Literature Education and Cultivation of College Students' Humanities Quality [J]. Journal of Changchun University of Science and Technology: Social Science Edition, 2014, (12). 